\title{
Role of Circadian Activation of Mitogen-Activated Protein Kinase in Chick Pineal Clock Oscillation
}

\author{
Kamon Sanada, Yuichiro Hayashi, Yuko Harada, Toshiyuki Okano, and Yoshitaka Fukada \\ Department of Biophysics and Biochemistry, Graduate School of Science, The University of Tokyo and CREST, Japan \\ Science and Technology Corporation, Tokyo 113-0033, Japan
}

A circadian pacemaker generates a rhythm with a period of $\sim 24 \mathrm{hr}$ even in the absence of environmental time cues. Several photosensitive neuronal tissues such as the retina and pineal gland contain the autonomous circadian pacemaker together with the photic-input pathway responsible for entrainment of the pacemaker to the daily light/dark cycle. We show here that, in constant darkness, chick pineal mitogen-activated protein kinase (MAPK) exhibited an in vivo circadian rhythm in tyrosine phosphorylation and in enzymatic activity with a peak during subjective night. Phosphorylated and hence activated MAPK was rapidly dephosphorylated after light illumination during the

Many organisms, from bacteria to humans, contain endogenous circadian pacemakers that control daily rhythms in behavior and physiology (Pittendrigh, 1993). These rhythms are synchronized (entrained) to a period of $24 \mathrm{hr}$ by environmental stimuli, most commonly by light, but they are sustained even under constant conditions (Takahashi, 1995; Dunlap, 1999). The circadian pacemaker seems to generally consist of positive/negative elements forming a transcription/translation-based negative feedback loop (Dunlap, 1999). The positive elements in the loop activate transcription of negative element genes and hence increase their protein levels (Crosthwaite et al., 1997; Darlington et al., 1998; Gekakis et al., 1998). The negative elements then inhibit the positive element-induced transactivation of their own promoters to decrease the transcript levels (Darlington et al., 1998). Thus, the levels of negative elements (and their mRNAs) exhibit a circadian oscillation. This fundamental frame of negative feedback loop may be ubiquitous because the negative and positive elements have been identified in a variety of organisms (Hardin et al., 1990; Aronson et al., 1994; Sehgal et al., 1995; Crosthwaite et al., 1997; King et al., 1997; Allada et al., 1998).

In addition to the transcriptional regulation of these clock genes, various post-translational mechanisms such as protein phosphorylation, nuclear entry, and proteolysis have been implicated in regulation of the circadian rhythmicity in the clock protein levels and their activities (Zeng et al., 1996; Garceau et al., 1997; Kloss et al., 1998; Lee et al., 1998; Price et al., 1998). These post-translational processes are likely to contribute to maintenance of period lengths of the molecular oscillations by

\footnotetext{
Received July 19, 1999; revised Nov. 5, 1999; accepted Nov. 11, 1999.

This work was supported in part by Grants-in-Aid from the Japanese Ministry of Education, Science, Culture, and Sports.

Correspondence should be addressed to Dr. Yoshitaka Fukada, Department of Biophysics and Biochemistry, Graduate School of Science, The University of Tokyo, Hongo 7-3-1, Bunkyo-Ku, Tokyo 113-0033, Japan. E-mail: sfukada@mail.ecc.utokyo.ac.jp.

Copyright (C) 2000 Society for Neuroscience $\quad 0270-6474 / 00 / 200986-06 \$ 15.00 / 0$
}

nighttime when light induces a phase-shift of the pacemaker. The circadian rhythmicity in MAPK phosphorylation was also observed in the cultured pineal gland, and importantly, MAPK kinase inhibitor treatment during subjective night not only shifted the time-of-peak of MAPK phosphorylation but also induced a remarkable phase-delay of the circadian pacemaker. These results indicate an important role of MAPK for time keeping in circadian clock systems.

Key words: circadian rhythm; pineal gland; tyrosine phosphorylation; mitogen-activated protein kinase; chick generating an appropriate time lag (Dunlap, 1999). Especially, protein phosphorylation plays a critical role in the circadian clock systems of various organisms (Roberts et al., 1989; Comolli et al., 1994; Zeng et al., 1996; Garceau et al., 1997; Lee et al., 1998), and an important contribution of PERIOD protein phosphorylation is clearly demonstrated in Drosophila (Kloss et al., 1998; Price et al., 1998). In vertebrates, however, less is known about the roles of protein phosphorylation in autonomous circadian pacemakers that are localized in specific neuronal tissues such as the suprachiasmatic nucleus (SCN), pineal gland, and retina (Deguchi, 1979; Kasal and Menaker, 1979; Green and Gillette, 1982; Cahill and Besharse, 1993; Tosini and Menaker, 1996). Because tyrosine kinases are particularly abundant in vertebrate neuronal tissues (van der Geer et al., 1994; Neet and Hunter, 1996), we have focused our attention on an involvement of protein tyrosine phosphorylation in the circadian pacemaker and light-input pathway. Among the clock containing tissues, the chick pineal gland retains both the pacemaker and photoreceptive molecules such as pinopsin within a single cell, and exhibits the circadian rhythm in melatonin production (Deguchi, 1979; Takahashi et al., 1980; Zatz et al., 1988; Okano et al., 1994; Nakahara et al., 1997). Thus, it represents a good organism for the study of the circadian clock systems in vertebrates. Here we report that chick pineal MAPK activity not only oscillates with a circadian rhythm but also affects the endogenous pacemaker oscillation, suggesting the participation of MAPK in the circadian feedback loop.

\section{MATERIALS AND METHODS}

Preparation of chick pineal homogenate. Animals were treated in accordance with the guidelines of University of Tokyo. Pineal glands were isolated from seven chicks and homogenized (10 strokes) using Teflon homogenizer with $150 \mu \mathrm{l}$ of ice-cold solution (10 mM Tris-HCl, $1 \mathrm{~mm}$ $\mathrm{Na}_{3} \mathrm{VO}_{4}, 4 \mu \mathrm{g} / \mathrm{ml}$ aprotinin, and $4 \mu \mathrm{g} / \mathrm{ml}$ leupeptin, $\mathrm{pH}$ 8.0). The homogenate was supplemented with $1 \%$ (w/v) SDS (final concentration), boiled for $5 \mathrm{~min}$, and then passed through a 26 gauge needle. Preparation of the pineal homogenate was performed under dim red light $(>640 \mathrm{~nm})$.

Immunoprecipitation. Pineal homogenate $(100 \mu \mathrm{l})$ was mixed with 900 
a
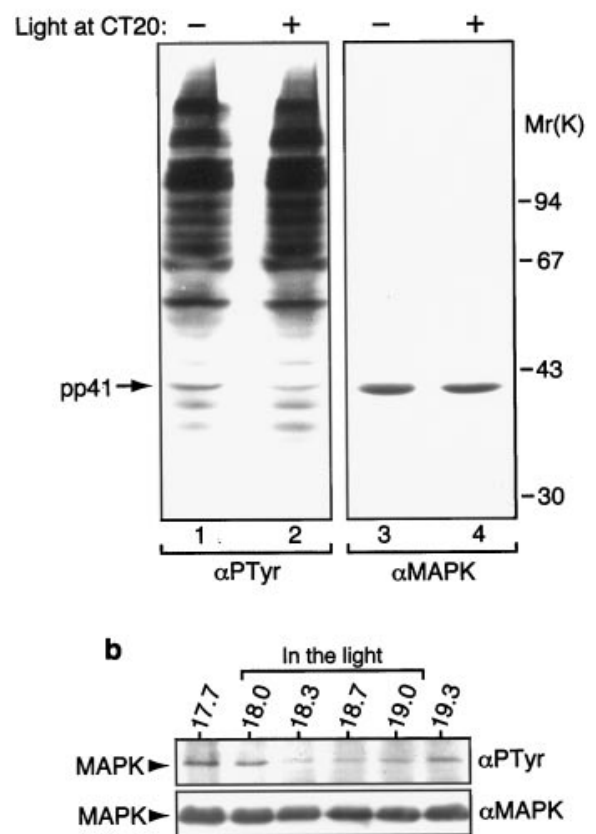

Figure 1. Tyrosine dephosphorylation of chick pineal MAPK after exposure to light. Chicks were entrained to a $12 \mathrm{hr}$ light/dark cycle for $7 \mathrm{~d}$ and then transferred to constant darkness. $a$, On day 8 , the pineal glands were isolated from chicks at CT 20 in the dark (lanes 1,3) or just after exposure to white light (200-300 lux) for 15 min (lanes 2, 4). The pineal homogenates were immunoblotted with anti-phosphotyrosine antibody (lanes 1,2), and the blot was reprobed with anti-MAPK antibody (lanes 3, 4). $b$, The chicks were exposed to white light (200-300 lux) at CT 18.0 on day 8 and then killed at CT 18.0, 18.3, 18.7, and 19.0 in the light. Control animals kept in the dark were killed at CT 17.7 and CT 19.3. MAPK in each pineal homogenate was immunoprecipitated, immunoblotted with anti-phosphotyrosine antibody (top panel), and then reprobed with antiMAPK antibody (bottom panel)

$\mu \mathrm{l}$ of ice-cold lysis buffer $[20 \mathrm{~mm}$ Tris-HCl, $1 \%$ (v/v) Triton X-100, 10\% (v/v) glycerol, $137 \mathrm{~mm} \mathrm{NaCl}, 2 \mathrm{~mm}$ EDTA, $50 \mathrm{~mm} \mathrm{NaF}, 1 \mathrm{~mm} \mathrm{Na} \mathrm{VO}_{4}$, $4 \mu \mathrm{g} / \mathrm{ml}$ aprotinin, and $4 \mu \mathrm{g} / \mathrm{ml}$ leupeptin, $\mathrm{pH}$ 8.0]. The lysate was precleared by incubation for $30 \mathrm{~min}$ with $50 \%$ slurry of protein G-Sepharose $(50 \mu \mathrm{l})$, and then incubated for $8 \mathrm{hr}$ at $4^{\circ} \mathrm{C}$ with $2.5 \mu \mathrm{g}$ of anti-PanERK antibody (Transduction Laboratories, Lexington, KY), followed by incubation with $50 \%$ slurry of protein G-Sepharose $(20 \mu \mathrm{l})$ for $4 \mathrm{hr}$ at $4^{\circ} \mathrm{C}$. The immunoprecipitates were washed three times with the lysis buffer and subjected to immunoblotting.

Immunoblotting. Proteins separated by SDS-polyacrylamide (13\% for Fig. $1 a$ or $8.5 \%$ for others) gels were transferred to polyvinylidene difluoride membranes. The blots were incubated at $37^{\circ} \mathrm{C}$ for $1 \mathrm{hr}$ with $1 \%$ (w/v) skim milk [or 3\% (w/v) BSA for anti-phosphotyrosine antibody] in TBS (in mM: 50 Tris- $\mathrm{HCl}, 140 \mathrm{NaCl}$, and $1 \mathrm{MgCl}_{2}, \mathrm{pH}$ 7.4), and then incubated at $4^{\circ} \mathrm{C}$ overnight with primary antibodies in the blocking solution. Phosphotyrosine was detected by anti-phosphotyrosine antibody (1:1000 dilution; Transduction Laboratories). MAPK was detected by anti-PanERK antibody (1:5000; Transduction Laboratories). Phosphorylated form of MAPK was detected by anti-phospho-MAPK antibody (1:2000, New England Biolabs, Beverly, MA). Tryptophan hydroxylase was detected by anti-tryptophan hydroxylase antibody (1:400; Chemicon, Temecula, CA). The blots were visualized by an enhanced chemiluminescence detection system (Renaissance; NEN). When reprobed, the blots were stripped according to manufacturer's protocol.

Immune complex kinase assay. MAPK was immunoprecipitated with anti-ERK2 antibody as described (Cook and McCormick, 1993), and MAPK activity in the immunoprecipitate was assayed at $30^{\circ} \mathrm{C}$ for $20 \mathrm{~min}$ in the presence of $10 \mu \mathrm{M}\left[\gamma^{-3} \mathrm{P}\right]$ ATP $(160 \mu \mathrm{Ci} / \mathrm{ml})$ and $8 \mu \mathrm{g}$ of myelin basic protein (MBP) as substrates. Proteins in the mixtures were resolved by SDS polyacrylamide $(13 \%)$ gel, and the incorporation of ${ }^{32} \mathrm{P}$ into MBP was quantitated using an image analyzer (FLA2000; Fujifilm, Tokyo, Japan).
Organ culture. One-day-old male chicks were entrained to a $12 \mathrm{hr}$ light/dark cycle for at least $7 \mathrm{~d}$. Chick pineal glands were cultured as described (Deguchi, 1979) with some modifications. In brief, the pineal glands were isolated 1-2 $\mathrm{hr}$ before the end of the light period, and then cultured on Millicell CM membranes (Millipore, Bedford MA; four glands in a cell of $30 \mathrm{~mm}$ diameter) in $1.9 \mathrm{ml}$ of BGJb medium supplemented with $10 \%$ heat-inactivated fetal calf serum, $100 \mu \mathrm{g} / \mathrm{ml}$ streptomycin sulfate, and $100 \mathrm{U} / \mathrm{ml}$ penicillin under $85 \% \mathrm{O}_{2}$ and $5 \% \mathrm{CO}_{2}$ at $38^{\circ} \mathrm{C}$. After the light period, the culture plates were transferred to constant darkness. To assess the phosphorylation state of MAPK, the cultured tissues (four pineal glands) were collected at various circadian times, rinsed with ice-cold TBS, and immediately homogenized (10 strokes) using Teflon homogenizer with $150 \mu \mathrm{l}$ of lysis buffer. The homogenate was then mixed with SDS-PAGE sample solution, boiled for $5 \mathrm{~min}$, and passed through a 26 gauge needle. Preparation of the tissue homogenate was performed under infrared light $(>800 \mathrm{~nm})$ with the aid of darkroom goggles (NEC, Tokyo, Japan).

Immunofluorescence microscopy. Cultured pineal glands were fixed with $4 \%(\mathrm{w} / \mathrm{v})$ paraformaldehyde in PBS (in mM: 10 Na-phosphate, 140 $\mathrm{NaCl}$, and $\left.1 \mathrm{MgCl}_{2}, \mathrm{pH} 7.4\right)$ for $1 \mathrm{hr}$ at $4^{\circ} \mathrm{C}$. The frozen sections $(10 \mu \mathrm{m}$ thickness) were incubated with $3 \%$ (w/v) BSA in PBS for $1 \mathrm{hr}$ at room temperature, and then incubated with anti-phospho-MAPK antibody (1:50; New England Biolabs) in the blocking solution for $18 \mathrm{hr}$ at $4^{\circ} \mathrm{C}$, followed by incubation with fluorescein-conjugated goat anti-rabbit IgG (1:500; Vector Laboratories, Burlingame, CA) in the blocking solution for $1 \mathrm{hr}$ at room temperature. The sections were mounted with Vectashield mounting medium plus 4',6-diamidino-2-phenylindole (DAPI) (Vector Laboratories) for viewing.

Superfusion culture. One-day-old male chicks were entrained to a light/dark cycle for at least $7 \mathrm{~d}$. Then the pineal glands were isolated and cultured individually in $10 \mathrm{~mm}$ wells of 48 well plates. The wells were sealed with silicon plugs that were equipped with inflow and outflow tubing. The culture chambers were kept at $38^{\circ} \mathrm{C}$ in $85 \% \mathrm{O}_{2}$ and $5 \% \mathrm{CO}_{2}$, and culture medium (see above) was delivered continuously to each
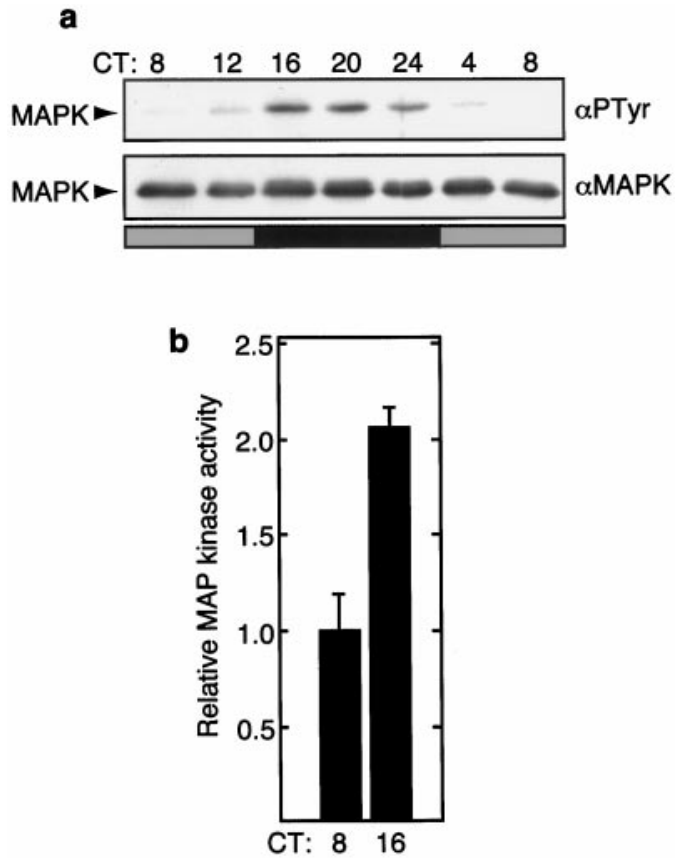

Figure 2. Circadian phosphorylation and activation of MAPK in the pineal gland. Chicks entrained to the light/dark cycle for $7 \mathrm{~d}$ were transferred to constant darkness (day 8), and their pineal glands were isolated every $4 \mathrm{hr}$ on days 8 and 9. MAPK was immunoprecipitated with anti-MAPK antibody from each pool of the pineal homogenates. $a$, The immunoprecipitates were immunoblotted with anti-phosphotyrosine antibody (top panel) and then reprobed with anti-MAPK antibody (bottom panel). Shaded and solid horizontal bars at the bottom indicate subjective day and night, respectively. $b$, The immunoprecipitates at CT 8 and CT 16 were subjected to immune complex kinase assay. The values are the means \pm range of variation of two independent measurements. 
a

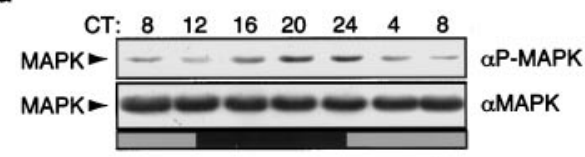

b

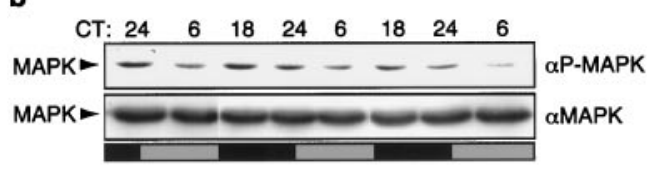

Figure 3. Circadian rhythm in MAPK phosphorylation in vitro. $a, b$, The pineal glands were cultured and collected at the indicated circadian time in the dark, from CT $8(a)$ or CT $24(b)$ on the second day of culture. Equal amounts of proteins $(20 \mu \mathrm{g})$ were immunoblotted with antiphospho-MAPK antibody (top panels) and then reprobed with antiMAPK antibody (bottom panels).

chamber by a peristaltic pump at a flow rate of $350 \mu \mathrm{l} / \mathrm{hr}$. The superfusion culture was started at a dark onset time on the first day of culture. The chambers were kept in one cycle (the first day) of $12 \mathrm{hr}$ dark/light and then transferred to constant darkness. Superfusate samples were collected every hour by a fraction collector.

Quantification of melatonin release by HPLC. Melatonin levels in the superfusate samples were determined by NANOSPACE HPLC system (Shiseido, Tokyo, Japan) consisted of two 2001 inert pumps, a 2003 autosampler, a 2004 column oven, a 2009 degassing unit, a 2013 fluorometric detector, and a H-P valve. The HPLC system was equipped with three columns; Capcell Pak C18 UG120 $(1.5 \times 150 \mathrm{~mm}$; Shiseido $)$ for a main separation, Capcell Pak C18 UG120 $(2.0 \times 35 \mathrm{~mm}$; Shiseido $)$ as an intermediate column, and MF Cartridge column $(4.0 \times 10 \mathrm{~mm}$; Shiseido) for a deproteinization as described (Shirota et al., 1995). These columns were kept at $40^{\circ} \mathrm{C}$. Superfusate samples were injected at a flow rate of 500 $\mu \mathrm{l} / \mathrm{min}$ onto the first MF Cartridge column equilibrated with Buffer P1 (100 mm Na-phosphate and $5 \mathrm{~mm}$ sodium 1-octanesulfonate, $\mathrm{pH} 5.0$ ). Molecules with large molecular weights such as serum proteins pass through the column, and small molecules such as melatonin are eluted with retardation. This melatonin-containing fraction was introduced to the intermediate Capcell Pak C18 column equilibrated with Buffer P1. Molecules bound to this column were eluted with Buffer P2 (100 mM Na-phosphate and $5 \mathrm{~mm}$ sodium 1-octanesulfonate, $\mathrm{pH}$ 3.0) supplemented with $20 \%(\mathrm{v} / \mathrm{v})$ acetonitrile at a flow rate of $100 \mu \mathrm{l} / \mathrm{min}$. The eluted molecules were separated by a main Capcell Pak C18 column with Buffer P2 supplemented with $20 \%$ (v/v) acetonitrile at a flow rate of 100 $\mu \mathrm{l} / \mathrm{min}$. The fluorescence intensity of the final eluate was monitored continuously with excitation and emission wavelengths set at 264 and 370 $\mathrm{nm}$, respectively. Under the chromatographic conditions, all metabolites produced from tryptophan in the melatonin synthesis were separated from melatonin. Melatonin levels were quantified by comparing the peak area of melatonin of samples with those obtained from known concentrations of standards. For measurement of phase shifts, melatonin rhythms were smoothed by a three-point running average to minimize the effects of random measurement error on phase determination. The times of half-rise and half-fall of the fourth and fifth circadian peaks were measured as phase reference points for each record. The phase shift was defined as the average of the differences from control in the phase reference points (Cahill and Besharse, 1993).

\section{RESULTS}

\section{Light-induced dephosphorylation of MAPK in the chick pineal gland}

Chicks were entrained to a $12 \mathrm{hr}$ light/dark cycle for 1 week and were subsequently kept in constant darkness. The pineal glands were isolated before and after exposure of chicks to light (for 15 min) at circadian time (CT) 20, which induces a phase-advance (Takahashi et al., 1989). Immunoblot analyses with antiphosphotyrosine antibody (Fig. 1a, left panel) demonstrated that the light illumination caused a decrease in the level of tyrosine phosphorylation of a $41 \mathrm{kDa}$ pineal protein (pp41). This protein seemed to represent a $42 \mathrm{kDa}$ serine-threonine kinase, MAPK [also called extracellular signal-regulated protein kinase (ERK)], because the pp41 migrated at the upper edge of an anti-MAPKimmunoreactive band (Fig. 1a, right panel), which is known to undergo mobility shift (de Vries-Smits et al., 1992) after dual phosphorylation of Thr-202 and Tyr-204 (Anderson et al., 1990; Davis, 1993). To test this, MAPK was immunoprecipitated from the chick pineal homogenate prepared at various time points during the light exposure of animals at subjective night, and the precipitates were immunoblotted with anti-phosphotyrosine antibody. As shown in Figure $1 b$, the level of tyrosine phosphorylation of MAPK noticeably decreased within 20 min after the onset of light at CT 18.0, whereas that of chicks kept in the darkness remained constant (Fig. 1b, CT 17.7 and 19.3). The MAPK protein levels estimated by PanERK antibody (Fig. 1b) and ERK2-specific antibody (data not shown) were almost constant during the experiment, indicating that chick pineal ERK2 is dephosphorylated after exposure of animals to light.

\section{Circadian activation of chick pineal MAPK}

In addition to the acute response to light, we observed an overt rhythm in the phosphorylation state of pineal MAPK in constant darkness. As shown in Figure $2 a$ (top panel), chick pineal MAPK
Figure 4. Localization of phosphorylated MAPK in the pineal gland. Thin frozen sections were prepared from the cultured pineal glands at CT 12 (left panels) or CT 24 (right panels) on the second day of culture and immunostained with anti-phosphoMAPK antibody. The nucleus was detected by staining with DAPI. Scale bars, $50 \mu \mathrm{m}$.
CT12

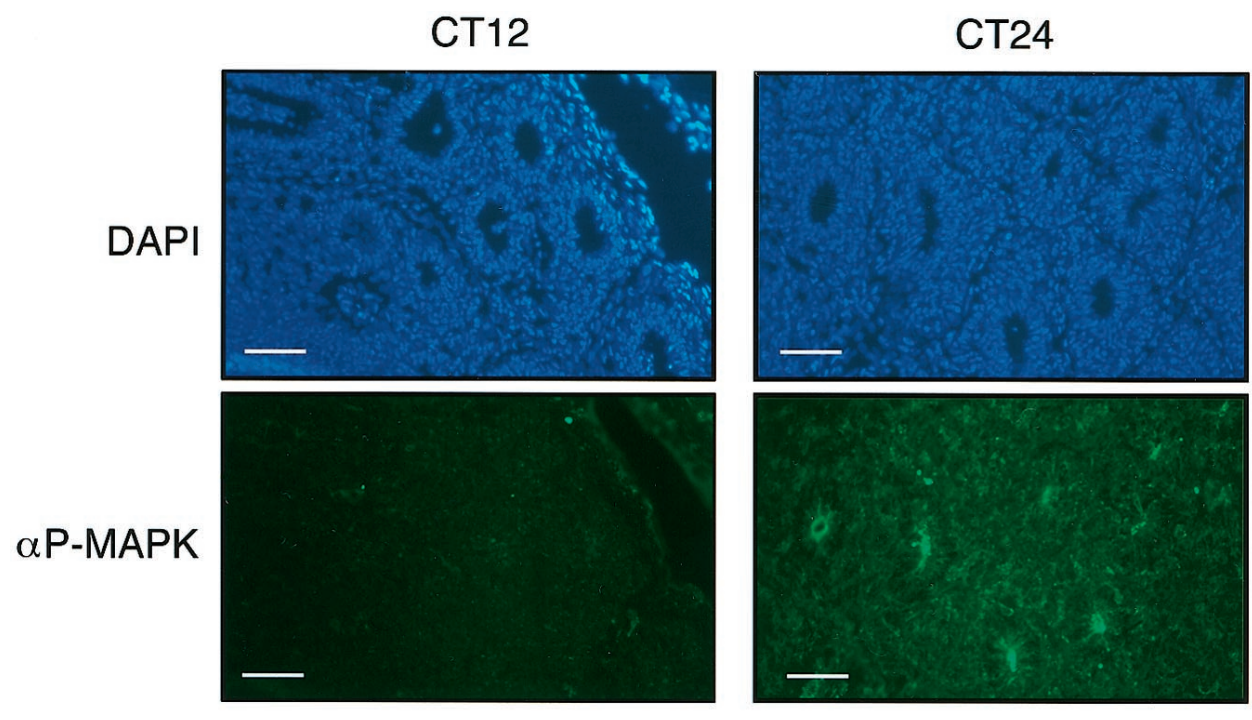



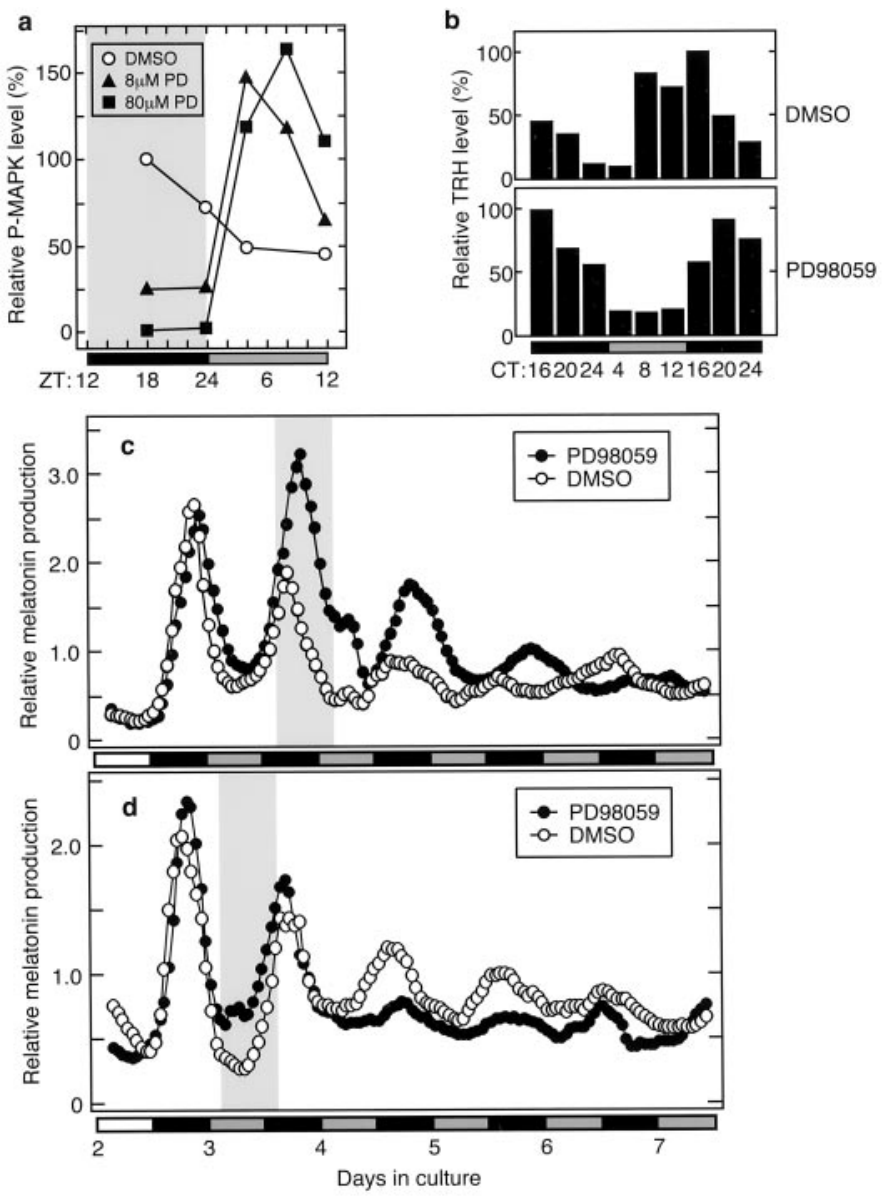

Figure 5. Effects of PD98059 on MAPK phosphorylation and the circadian pacemaker. $a$, Cultured pineal glands were treated with PD98059 (80 or $8 \mu \mathrm{M})$ in $0.1 \%$ DMSO for $12 \mathrm{hr}(\mathrm{ZT} 12-24$, gray area) on the first day of culture or with $0.1 \%$ DMSO as a control. Pineal glands were collected at the indicated time, and equal amounts of the pineal proteins $(20 \mu \mathrm{g})$ were immunoblotted with anti-phospho-MAPK antibody. Phosphorylated MAPK levels were quantified by a densitometry. The means of two experiments are shown in values relative to the band density of control $(100 \%)$ at ZT 18. b. Cultured pineal gland was treated with $80 \mu \mathrm{M}$ PD98059 or DMSO for $11 \mathrm{hr}$ from ZT 12 as in $a$. Pineal glands were collected every $4 \mathrm{hr}$ on the second and third day of culture, and each pool of the homogenates ( $20 \mu \mathrm{g}$ proteins) was immunoblotted with anti-TRH antibody. TRH levels were quantitated by a densitometry and shown in values relative to the peak value set to $100 \%$. The data are representative results of replicate experiments with similar results. $c, d$, Pineal glands were cultured individually in superfusion culture chambers and were treated with $80 \mu \mathrm{M}$ PD98059 (closed circles) in $0.1 \%$ DMSO or with $0.1 \%$ DMSO (open circles) for $12 \mathrm{hr}$ from CT $15(c)$ or CT $3(d)$ in constant darkness. Melatonin levels in the superfusate samples were determined by HPLC. Melatonin levels for each pineal gland were shown in values relative to the average melatonin release on the second day of culture. The data are representative results of three independent pairs of experiments. The treatment with PD98059 from CT $15(c)$ induced a phasedelay of $4.8 \pm 1.3 \mathrm{hr}$ (mean $\pm \mathrm{SE}, n=3)$, whereas that from CT $3(d)$ induced no significant phase-shift $(n=3)$.

was tyrosine-phosphorylated during subjective night with a peak at CT 16-20, and it becomes dephosphorylated during subjective day without any significant change in the protein level (bottom panel). Time-of-day specific activation of MAPK (i.e., activation in subjective night) caused by the dual phosphorylation was confirmed by an immune complex kinase assay (Fig. $2 b$ ).

To determine whether the activation rhythm of MAPK is associated with the endogenous pacemaker in the chick pineal gland, the state of MAPK phosphorylation was characterized in cultured pineal glands by using anti-phospho-MAPK antibody, which specifically recognizes dually phosphorylated (activated) MAPK. The rhythmicity of MAPK phosphorylation was observed in culture under constant darkness (Fig. 3a, top panel) with a peak at mid-to-late subjective night (CT 16-24), whereas MAPK protein levels were nearly constant (bottom panel). The rhythmicity persisted for at least $2 \mathrm{~d}$ in constant darkness (Fig. $3 b$ ), confirming that the molecular cycle reflects bona fide circadian regulation. To localize the site of MAPK phosphorylation, pineal sections (10 $\mu \mathrm{m}$ thickness) were prepared from the cultured tissues at CT12 and 24 (representing inactivated and activated phases, respectively; Fig. $3 a$ ), and they were subjected to immunostaining by anti-phospho-MAPK antibody. No immunoreactivity was observed in the pineal section prepared at $\mathrm{CT} 12$, whereas at CT 24 strong immunoreactivities were found in the luminal layers of almost all the follicles (Fig. 4). These follicular pinealocytes have pineal photoreceptor pinopsin (Okano et al., 1994, 1997) and enzymes in melatonin biosynthesis, among which $\mathrm{N}$-acetyltransferase and hydroxyindole- $\mathrm{O}$-methyltransferase are known to colocalize with the circadian pacemaker (Greve et al., 1993; Bernard et al., 1997; Nakahara et al., 1997). Taken together, our observations strongly suggest an intracellular linkage between circadian phosphorylation of MAPK and the pacemaker.

\section{Involvement of MAPK in the circadian timing mechanism}

Then we questioned the role of MAPK in a circadian rhythm by examining the effect of pulse perturbation of pineal MAPK activity on the phase of the circadian clock. To this end, we used PD98059, a reversible inhibitor of MAPK kinase (MEK) that is responsible for the dual phosphorylation and activation of MAPK (Alessi et al., 1995). Cultured chick pineal glands were treated with PD98059 for $12 \mathrm{hr}$ from Zeitgeber time (ZT) 12, and the level of MAPK phosphorylation was investigated during and after the treatment in the darkness. Nighttime phosphorylation of MAPK was inhibited by PD98059 in a dose-dependent manner, and $80 \mu \mathrm{M}$ PD98059 completely suppressed the phosphorylation (Fig. 5a). When the drug was removed, the phosphorylation level began to increase rapidly, peaking at 4-8 hr after the removal, and then decreased. During this period, MAPK protein levels were nearly constant (data not shown). Such an apparent shift of peak time in MAPK phosphorylation suggests a drug-induced phase-shift of the circadian pacemaker. This idea was tested by measuring circadian variations of two kinds of established outputs from the chick pineal pacemaker. One is a circadian variation in tryptophan hydroxylase (TRH) protein level in constant darkness (Florez and Takahashi, 1996). Eleven hour pretreatment (ZT 12-23) of cultured pineal glands with $80 \mu \mathrm{M}$ PD98059 induced a delay of the time-of-peak by $4-8 \mathrm{hr}$ (Fig. $5 b$, bottom panel) as compared to a control experiment (top panel). In the other assessment of the effect of PD98059, a circadian variation of the pineal melatonin production was measured by using superfusion culture (Takahashi et al., 1980). To verify that PD98059 specifically affects the circadian pacemaker, we examined whether its effect is dependent on the circadian phase at which it is presented. Then $12 \mathrm{hr}$ treatment from CT 15 (Fig. 5c) induced a clear phase-delay of $4.8 \pm 1.3 \mathrm{hr}$ (mean $\pm \mathrm{SE}, n=3$ ). In contrast, similar treatment during a frame covering most of subjective daytime (CT 3-15) did not affect the phase of the rhythm (Fig. $5 d$ ). This phase-dependent effect demonstrates that PD98059 is a genuine phase-shifting agent, and it is unlikely that PD98059 
serves to arrest cell activity. Similar circadian variation in MAPK phosphorylation and the phase-shifting effect of PD98059 were also observed in another clock-containing tissue, bullfrog retina (Y. Harada, K. Sanada, and Y. Fukada, unpublished observations), indicating that MAPK is an important component in the circadian timing mechanism in vertebrates.

\section{DISCUSSION}

Our results provide the first evidence that MAPK contributes to circadian time keeping in the chick pineal glands. The phosphorylation rhythm of MAPK seems to reflect an overall oscillation of the MAPK cascade, because we observed a clear circadian oscillation in kinase activities of MEK and Raf in the chick pineal gland (Y. Hayashi, K. Sanada, and Y. Fukada, unpublished observations). It is possible that some of upstream regulators of the MAPK cascade are controlled at the transcriptional level by an autoregulatory feedback loop (Takahashi, 1995; Dunlap, 1998; Reppert, 1998), and that MAPK mediates feedback of the output back to input, forming a secondary loop. These interconnected loops could determine the circadian properties such as period length (Dunlap, 1998, 1999). Alternatively, MAPK cascade may be activated by intercellular communication and mediate coupling of pacemakers among clock cells. In the circadian feedback loop, some of the essential clock components exhibit a daily/ circadian rhythm in the level of phosphorylation (Zeng et al., 1996; Lee et al., 1998). MAPK might be one of the upstream kinases responsible for phosphorylating and regulating the biochemical activities (and stabilities) of the clock proteins or other components such as cAMP response element-binding protein, which has been implicated in circadian regulation of period gene expression (Belvin et al., 1999).

Recently it was reported that MAPK phosphorylation exhibited a circadian variation in the mouse SCN (Obrietan et al., 1998), although its involvement in the pacemaker machinery was not evaluated. Noticeably, the circadian rhythmicity of MAPK phosphorylation in the mouse SCN had a peak during subjective day (Obrietan et al., 1998), whereas those in the chick pineal gland (Fig. 2, 3) and frog retina (Y. Harada, K. Sanada, and Y. Fukada, unpublished observations) did during subjective night. A more marked contrast is the acute effect of light; that is, MAPK in the chick pineal gland (Fig. 1) is rapidly dephosphorylated after nighttime light illumination, which induces inversely phosphorylation of MAPK in the mouse SCN. Despite such a contrast, the MAPK cascade may be involved in a common oscillator function in vertebrate clock systems. Signal transduction pathways upstream and downstream of the MAPK cascade and regulation of MAPK phosphatase are to be investigated for better understanding of the relationship between the MAPK cascade and the circadian oscillation mechanism in vertebrates.

\section{REFERENCES}

Alessi DR, Cuenda A, Cohen P, Dudley DT, Saltiel AR (1995) PD098059 is a specific inhibitor of the activation of mitogenactivated protein kinase kinase in vitro and in vivo. J Biol Chem 270:27489-27494.

Allada R, White NE, So WV, Hall JC, Rosbash M (1998) A mutant Drosophila homolog of mammalian CLOCK disrupts circadian rhythms and transcription of period and timeless. Cell 93:805-814.

Anderson NG, Maller JL, Tonks NK, Sturgill TW (1990) Requirement for integration of signals from two distinct phosphorylation pathway for activation of MAP kinase. Nature 343:651-653.
Aronson B, Johnson K, Loros JJ, Dunlap JC (1994) Negative feedback defining a circadian clock: autoregulation in the clock gene frequency. Science 263:1578-15684.

Belvin MP, Zhou H, Yin JCP (1999) The Drosophila dCREB2 gene affects the circadian clock. Neuron 22:777-787.

Bernard M, Iuvone PM, Cassone VM, Roseboom PH, Coon SL, Klein DC (1997) Avian melatonin synthesis: photic and circadian regulation of serotonin $N$-acetyltransferase mRNA in the chicken pineal gland and retina. J Neurochem 68:213-224.

Cahill GM, Besharse C (1993) Circadian clock functions localized in Xenopus retinal photoreceptors. Neuron 10:573-577.

Comolli J, Taylor W, Hastings JW (1994) An inhibitor of protein phosphorylation stops the circadian oscillator and blocks light-induced phase shifting in Gonyaulax polyedra. J Biol Rhythm 9:13-26.

Cook SJ, McCormick F (1993) Inhibition by cAMP of Ras-dependent activation of Raf. Science 262:1069-1072.

Crosthwaite SC, Dunlap JC, Loros JJ (1997) Neurospora wc-1 and wc-2 transcription, photoresponses and the origin of circadian rhythmicity. Science 276:763-769.

Darlington TK, Wagar-Smith K, Ceriani MF, Staknis D, Gekakis N, Steeves TDL, Weitz CJ, Takahashi JS, Kay SA (1998) Closing the circadian loop: CLOCK-induced transcription of its own inhibitors per and tim. Science 280:1500-1603.

Davis RJ (1993) The mitogen-activated protein kinase signal transduction pathway. J Biol Chem 268:14553-14556.

Deguchi T (1979) Circadian rhythm of serotonin- $N$-acetyltransferase activity in organ culture of chicken pineal gland. Science 203:1245-1247.

de Vries-Smits AMM, Th. Burgering BM, Leevers SJ, Marshall CJ, Bos JL (1992) Involvement of p21 ras in activation of extracellular signalregulated kinase 2. Nature 357:602-604.

Dunlap J (1998) Circadian rhythms. An end in the beginning. Science 280:1548-1549.

Dunlap JC (1999) Molecular bases for circadian clock. Cell 96:271-290.

Florez JC, Takahashi JS (1996) Quantitative two-dimensional gel electrophoretic analysis of clock-controlled proteins in cultured chick pineal cells: circadian regulation of tryptophan hydroxylase. J Biol Rhythm 11:241-257.

Garceau NY, Liu Y, Loros JJ, Dunlap JC (1997) Alternative initiation of translation and time-specific phosphorylation yield multiple forms of the essential clock protein FREQUENCY. Cell 89:469-476.

Gekakis N, Staknis D, Nguyen HB, Davis FC, Wilsbacher LD, King DP, Takahashi JS, Weitz CJ (1998) Role of the CLOCK protein in the mammalian circadian mechanism. Science 280:1564-1569.

Green DJ, Gillette R (1982) Circadian rhythm of firing rate recorded from single cells in the rat suprachiasmatic brain slice. Brain Res 245:198-200.

Greve P, Voisin P, Grechez-Cassiau A, Bernard M, Collin JP, Guerlotte J (1993) Cellular localization of hydroxyindole- $O$-methyltransferase mRNA in the chicken pineal gland. NeuroReport 4:803-806.

Hardin PE, Hall JC, Rosbash M (1990) Feedback of the Drosophila period gene product on circadian cycling of its messenger RNA levels. Nature 343:536-540.

Kasal CH, Menaker M (1979) Circadian clock in culture: $N$-acetyltransferase activity of chicken pineal glands oscillates in vitro. Science 203:656-658.

King DP, Zhao Y, Sangoram AM, Wilsbacher LD, Tanaka M, Antoch MP, Steeves TDL, Vitaterna MH, Kornhauser JM, Lowrey PL, Turek FW, Takahashi JS (1997) Positional cloning of the mouse circadian Clock gene. Cell 89:641-653.

Kloss B, Price JP, Saez L, Blau J, Rothenfluh A, Wesley CS, Young MW (1998) The Drosophila clock gene double-time encodes a protein closely related to human casein kinase I $\epsilon$. Cell 94:97-107.

Lee C, Bae K, Edery I (1998) The Drosophila CLOCK protein undergoes daily rhythms in abundance, phosphorylation, and interactions with PER-TIM complex. Neuron 21:857-867.

Nakahara K, Murakami N, Nasu T, Kuroda H, Murakami T (1997) Individual pineal cells in chick possess photoreceptive, circadian clock and melatonin-synthesizing capacities in vitro. Brain Res 774:242-245.

Neet K, Hunter T (1996) Vertebrate non-receptor protein-tyrosine kinase families. Genes Cells 1:147-169.

Obrietan K, Impey S, Storm DR (1998) Light and circadian rhythmicity regulate MAP kinase activation in the suprachiasmatic nuclei. Nat Neurosci 1:693-700. 
Okano T, Yoshizawa T, Fukada Y (1994) Pinopsin is a chicken pineal photoreceptive molecule. Nature 372:94-97.

Okano T, Takanaka Y, Nakamura A, Hirunagi K, Adachi A, Ebihara S, Fukada Y (1997) Immunohistochemical identification of pinopsin in the pineal glands of chicken and pigeon. Mol Brain Res 50:190-196.

Pittendrigh CS (1993) Temporal organization: reflections of a Darwinian clock-watcher. Annu Rev Physiol 55:16-54.

Price JL, Blau J, Rothenfluh A, Abodeely M, Kloss B, Young MW (1998) double-time is a novel Drosophila clock gene that regulates PERIOD protein accumulation. Cell 94:83-95.

Reppert SM (1998) A clockwork explosion! Neuron 21:1-4.

Roberts MH, Bedian V, Chen Y (1989) Kinase inhibition lengthens the period of the circadian pacemaker in the eye of Bulla gouldiana. Brain Res 504:211-215.

Sehgal A, Rothenfluh-Hilfiker A, Hunter-Ensor M, Chen Y, Myers MP, Young MW (1995) Rhythmic expression of timeless: a basis for promoting circadian cycles in period gene autoregulation. Science 270:808-810.

Shirota O, Suzuki A, Kanda T, Ohtsu Y, Yamaguchi M (1995) Low concentration drug analysis by semi-microcolumn liquid chromatogra- phy with a polymer-coated mixed-function precolumn. J Microcol Sep 7:29-35.

Takahashi JS (1995) Molecular neurobiology and genetics of circadian rhythms in mammals. Annu Rev Neurosci 18:531-553.

Takahashi JS, Hamm H, Menaker M (1980) Circadian rhythms of melatonin release from individual superfused chicken pineal glands in vitro. Proc Natl Acad Sci USA 77:2319-2322.

Takahashi JS, Murakami N, Nikaido SS, Pratt BL (1989) The avian pineal, a vertebrate model system of the circadian oscillator. Recent Prog Horm Res 45:279-352.

Tosini G, Menaker M (1996) Circadian rhythms in cultured mammalian retina. Science 272:419-421.

van der Geer P, Hunter T, Lindberg RA (1994) Receptor proteintyrosine kinases and their signal transduction pathways. Annu Rev Cell Biol 10:251-337.

Zatz M, Mullen DA, Moskal JR (1988) Photoendocrine transduction in cultured chick pineal cells: effects of light, dark and potassium on the melatonin rhythm. Brain Res 438:199-215.

Zeng H, Qian Z, Myers MP, Rosbash M (1996) A light-entrainment mechanism for the Drosophila circadian clock. Nature 380:129-135. 